\title{
Using Insights from Behavioral Economics to Mitigate the Spread of COVID-19
}

\author{
Moslem Soofi ${ }^{1} \cdot$ Farid Najafi $^{2} \cdot$ Behzad Karami-Matin $^{2}$
}

Published online: 21 May 2020

○) Springer Nature Switzerland AG 2020

\begin{abstract}
The outbreak of 2019 coronavirus disease (COVID-19) has become a public health emergency of international concern. The number of COVID-infected individuals and related deaths continues to rise rapidly. Encouraging people to adopt and sustain preventive behaviors is a central focus of public health policies that seek to mitigate the spread of COVID-19. Public health policy needs improved methods to encourage people to adhere to COVID-19-preventive behaviors. In this paper, we introduce a number of insights from behavioral economics that help explain why people may behave irrationally during the COVID-19 pandemic. In particular, present bias, status quo bias, framing effect, optimism bias, affect heuristic, and herding behavior are discussed. We hope this paper will shed light on how insights from behavioral economics can enrich public health policies and interventions in the fight against COVID-19.
\end{abstract}

\section{Key Points for Decision Makers}

Behavioral economics acknowledges that people are not the rational decision makers assumed in the standard economic theory of decision making.

Finite rationality and willpower lead people to apply the rules of thumb or heuristics to make their COVID19-related decisions rather than conducting cost-benefit analyses. Therefore, they may be biased in their COVID19-related decisions.

Behavioral economics can help policy makers identify individuals' decision biases and use them as starting points for designing COVID-19-preventive interventions. Behavioral economics interventions can help people behave rationally and make better COVID-19-related decisions.

Behzad Karami-Matin

bkm_1344@yahoo.com

1 Social Development and Health Promotion Research Center, Health Institute, Kermanshah University of Medical Sciences, Kermanshah, Iran

2 Research Center for Environmental Determinants of Health, Health Institute, Kermanshah University of Medical Sciences, Kermanshah, Iran

\section{Introduction}

The outbreak of 2019 coronavirus disease (COVID-19) has become a public health emergency of international concern [1]. The number of COVID-infected individuals and related deaths continues to rise rapidly. COVID-19 is a serious threat to global health and the world economy and has caused widespread concern around the world. In the absence of approved treatments for and vaccines against COVID-19, preventive strategies and hygiene behaviors such as social distancing and stay-at-home policies, avoiding touching the face, and repeated hand washing are effective options in the fight against COVID-19 [2, 3]. During this pandemic, encouraging people to adopt and sustain preventive behaviors is a central focus of public health policies that seek to mitigate the spread of COVID-19.

Behavioral economics has recently received a great deal of attention in public policy making [4]. This field of economics uses insights from the fields of psychology, neuroscience, and cognitive sciences to explain how people's behaviors deviate from the rational choice theory and when and why people's short-term decisions sometimes undermine their long-term interests. The focus of this field is on better predicting and understanding people's behaviors and choices to help formulate more effective public policies [5, 6]. It identifies biases in the decision-making process and uses them as entry points for interventions to address particular behaviors.

Behavioral economics acknowledges that people do not have infinite rationality and willpower, so they are not the 
rational decision makers assumed in the standard economic theory of utility maximization $[6,7]$. In addition, they have limited cognitive and computational abilities, and their decisions are not based on a complete analysis of all available information [6]. These limitations lead people to apply the rules of thumb or heuristics (i.e., mental shortcuts) to make their decisions rather than conducting cost-benefit analyses when making a decision. The heuristics are generally useful but can lead to systematic mistakes (i.e., biases) in decision making that, in turn, result in suboptimal and harmful behaviors $[5,8]$.

Behavioral economics has shed new light on a range of risky and preventive health behaviors [9]. It also has considerable potential for providing a valuable perspective to better understand and explain COVID-19-related behaviors. While multiple biases are identified in the field of behavioral economics, in this paper we focus on six that tend to be particularly relevant to COVID-19-related behaviors: present bias, status quo bias, framing effect, optimism bias, affect heuristic, and herding behavior. It may provide useful insights into public health policies designed to reduce the spread of COVID-19 and may be helpful in developing and implementing interventions.

\section{Present Bias}

In the context of intertemporal choices, the costs and benefits of our choices occur at different points in time, that is, many daily choices are a trade-off between immediate outcomes (i.e., costs and benefit) and expected future outcomes [10]. Present bias or hyperbolic discounting is the nonlinear and nonconstant tendency of many individuals to prefer a smaller sooner pay-off over a larger future pay-off [11-13]. Present bias may lead to time-inconsistent preferences. An individual makes a plan for tomorrow, but once tomorrow comes they may experience a preference reversal and revise their plan. Present bias has been shown to be a significant predictor of a wide variety of health behaviors [14]. Many health behaviors involve a trade-off between immediate and future outcomes. For example, smoking has both current benefits (temporary stress relief) and future costs (increased risk of lung cancer) [10]. In the case of COVID-19, not adhering to stay-at-home policies involves a trade-off between the pleasure of going to the mall or restaurant now (current benefit) and the increased risk of contracting COVID-19 in the future (uncertain future cost). Uncertain future cost means that not every excursion outside the house would result in COVID-19 infection. Thus, myopic individuals (i.e., those with present bias), who put a greater emphasis on the here and now, are less likely to adhere to COVID-19-preventive behaviors, including staying at home and hand washing. Present bias is an explanation for why people do not behave in their own best interests and why they have difficulty adhering to preventive health behaviors such as social distancing, even when they wish to adhere [15].

Although present bias may lead to suboptimal behavioral choices, it can be used to help people adhere to COVID19-preventive behaviors [12]. For example, reducing the current costs of adherence to social distancing may help people overcome their present bias, as even small costs could outweigh any perceived future benefits of adherence. Increasing the current benefit of adherence to social distancing, such as offering small and frequent payments now, can be useful in encouraging people to adhere to COVID-19-preventive behaviors. Such interventions involving low-cost rewards have been used as ways to increase current benefits of adherence to antiretroviral medication [16], smoking cessation [17], and weight loss [18], and they have been shown to be effective in changing behaviors. To reduce COVID-19 transmission, in the short term, providing free internet access at home, temporary suspension of loan repayments (e.g., loans provided by the government to support unemployed and uninsured people to start small businesses), and providing benefit packages for vulnerable groups should be considered in stay-at-home policies to encourage people to adhere to the policy and to increase its success rate.

\section{Status Quo Bias and Default Options}

Status quo bias is a disproportionate preference for the current status of options and an unwillingness to change them $[19,20]$. One reason for this is that people interpret the potential disadvantages of changing the status quo as greater than the potential benefits. This bias can be turned to the advantage of encouraging health-enhancing behaviors through the use of "nudges". The concept of "nudge" was introduced in behavioral economics to persuade individuals to behave rationally and make better choices. Thaler and Sunstein [5] defined a nudge as "any aspect of the choice architecture that influences individuals' decision making in a predictable way without forbidding any options or changing economic incentives." They argued that, by improving and altering the environment in which individuals make decisions - what they call the "choice architecture"-, individuals can be influenced to make smarter choices. Choice architecture can be used to build an environment in which it is easier to make optimal health choices and more difficult to select suboptimal ones. The default option is a nudge with a powerful impact on directing the behaviors of people in ways that meet their long-term interests [5]. One of the most notable examples of the default option is organ donation. Countries with an opt-out system (consent to donate is assumed, and the default option is to donate organs) have a considerably higher rate of organ donation than countries with an opt-in system (default option is not to donate organs) 
[21]. Positive effects from the default option have also been reported for vaccination uptake [22] and the rate of enrollment into a diabetes management program [23]. COVID19-prevention policies can also nudge people to engage in hygiene practices such as repeated hand washing by arranging defaults in the environment where they make COVID19-related choices. For example, soaps with toys embedded inside improved hand washing behavior in children [24]. This example is a choice architecture (i.e., nudge) that may nudge children to wash their hands more frequently, so could be used to increase hand washing during this COVID-19 outbreak. A field experiment study in India found that the installation of low-cost soap dispensers in homes improved hand washing in peri-urban and rural households [25].

\section{Framing Effect}

Framing effect refers to the fact that individuals' choices often depend on the way the choices are described, or framed, and that these choices are often affected by whether the possible outcomes are framed in terms of the gains or the losses [26]. This concept is closely associated with loss aversion, which implies that the disutility caused by a given amount of loss is about twice the utility of gaining the same amount. For example, the statements "the odds of survival after 1 month of surgery are $90 \%$ " and "the odds of mortality within 1 month of surgery are 10\%" elicit different reactions. Both statements offer the same information, but many individuals react differently to the risk of surgery when presented as a $90 \%$ chance of survival versus a $10 \%$ chance of death [27].

The framing effect has application for directing individuals toward health-promoting decisions and has been examined in a wide variety of health behaviors [28]. A health message can be framed to emphasize the benefits (i.e., gainframed message) of performing a specific behavior or to emphasize the disadvantages (i.e., loss-framed message) of not engaging in that behavior [29]. Studies have shown that loss-framed messages are often more effective for disease-detection behaviors such as uptake of cancer screening, whereas gain-framed messages are often more effective for promoting preventive behaviors. A meta-analysis of 94 studies found that health messages framed as gains or benefits were significantly more likely to increase preventive behaviors than those framed as losses [29]. It offers a helpful perspective for framing health messages regarding COVID-19 prevention. It seems that health messages intended to encourage people to engage in COVID-19-preventive behaviors (e.g., social distancing) should be framed in terms of gains, such as "If you wash your hands properly/ follow social distancing policy/adhere to the stay-at-home policy, you will increase the chances of yourself and your family having a long, healthy life."

\section{Optimism and Overconfidence}

People display unrealistic optimism about their vulnerability to a wide set of negative outcomes [30] and often see themselves as being at less-than-average risk of negative outcomes. Optimism bias is people's tendency to estimate the probability of positive future outcomes as greater than average and that of negative future outcomes as less than average $[30,31]$. This may lead people to unwittingly take extra risks with their own health and more than they would if they were aware of the objective risk of health-related behavior [32]. This can help explain a wide range of risktaking behaviors, including health-related decisions. For example, one study revealed that smokers underestimated their risk of developing lung cancer compared with that of other smokers and even non-smokers [33]. Another study found that people with a subjective risk lower than their objective risk were more likely to support the belief that there is no risk of lung cancer if you just smoke for a few years and to believe that a large number of patients with lung cancer are cured. They were even less likely to decide to stop smoking [34]. People realize the risk of getting COVID-19 from suboptimal behaviors such as not washing hands or not adhering to social distancing but are likely to believe that they are less likely than other people or their peers to get COVID-19, even if their peers adhere to preventive practices. Providing peer comparison feedback or communicating risks accurately can be helpful for addressing optimism and overconfidence bias. In addition, priming an outcome by presenting what has happened to individuals or populations that are considered peers may persuade people to adhere to preventive behaviors [35]. For example, adolescents may become more engaged in COVID-19-prevention programs if they are aware that an adolescent celebrity contracted COVID-19. A possible explanation for this may be that the COVID-19 infection of an adolescent celebrity tends to increase the perception of individuals regarding their personal risk of getting COVID-19.

\section{Affect Heuristic}

Affect heuristic is a person's tendency to judge risks and benefits based on their affect, that is, different affects can produce different risk and benefit perceptions [36]. It has been shown that individuals' affect acts as a form of information that they refer to when deciding whether to engage in particular health behaviors $[37,38]$. In particular, when people feel positive about a behavior, they judge its risks as low and benefits as high; when they feel negative about a behavior, they judge its risks as high and benefits as low [39]. Evidence has shown that, while risk and benefit appear to be 
often uncorrelated or even positively correlated across harmful behaviors in the real-world context (i.e., high-risk activity appears to be highly gainful), they are often negatively correlated in individuals' judgments and decisions (i.e., high risk is associated with low profit and vice versa) $[36,39]$. A study found that test harm information about prostatespecific antigen screening for prostate cancer and magnetic resonance imaging reduced perceived test benefits [40]. A study of how affect influences individuals' processing of messages about risks and benefits of using autonomous artificial intelligence technology to screen for skin cancer found that integral artificial intelligence affect impacted on individuals' perception of risk and benefits based on messages provided, which then influenced the probability of using artificial intelligence technology for health [41]. If perceptions of risk and benefit are directed by affect, the provision of benefits information will switch people's judgment of risk and vice versa [39]. Therefore, the messages that people receive about a certain behavior become an important source of information that influences their health decisions [37]. This heuristic suggests that policy maker's efforts to create negative feelings toward not adhering to COVID-19-preventive behaviors can increase the perceived risks associated with not adhering. For example, if an individual is told that not adhering to social distancing policy might cause them to contract COVID-19, this is predicted to cause negative feelings toward not adhering, which should, in turn, reduce the perceived benefits of not adhering to social distancing. In addition, "don't miss the opportunity to be together at home" may be helpful for encouraging people to adhere to stay-athome policies. A controlled trial in India showed that a scalable village-level intervention based on emotional drivers of behavior was more successful at increasing hand washing than was providing information [42].

\section{Herding Behavior and Social Influence}

Social norms and the behavior of peers such as friends, family members, and colleagues affect behaviors. Herding behavior occurs when people consider a certain behavior to be good or bad based on the behavior of other people and mimic their observed behaviors [43]. This characteristic of human behavior is well-established in a number of fields, particularly economics and finance [44]. One implication of this behavior is that if a policy aims to encourage people to make a health decision, then it needs to inform individuals about the behavior of other people and their peers [5]. In a real-world experiment conducted on tax compliance in Minnesota, one of the interventions informed people that more than $90 \%$ of Minnesotans had paid their taxes; this had a significant effect on tax compliance compared with other interventions $[5,45]$. To nudge people to adhere to social distancing policy, interventions should draw attention to what other people are doing [5]. For example, telling people that "the majority of the people in your neighboring city or province are following the social distancing/stay-at-home policy" may increase adherence to social distancing policy.

\section{Conclusion}

We have discussed insights from behavioral economics that shed light on how to help people engage in COVID-19-preventive behaviors. This paper can improve our understanding of the decision-making biases that can be applied as entry points in public health policies and interventions for the prevention of COVID-19. They may assist policy makers in identifying novel interventions to improve decision making and behaviors related to the prevention of COVID-19. We provided some policy suggestions that may be useful in the fight against COVID-19, summarized as follows: reduce the current costs or increase the current benefits of adherence to social distancing/stay-at-home policies, arrange defaults in environments where people make COVID-19-related choices (i.e., choice architecture), design gain-framed messages for COVID-19-preventive behaviors, prime contamination with COVID-19 by presenting examples pertinent to a specific population, create negative feelings toward not adhering to COVID-19-preventive behavior, and draw individual's attention to what other individuals are doing about COVID-19-related decisions. While many health-related behaviors have been shown to be associated with the six decision biases discussed, the degree to which they impact COVID-19-preventive behaviors has not yet been empirically investigated. Future work should examine strategies such as gain-framed messages, incentives in terms of small frequent rewards, and default options or nudges to improve interventions designed to prevent not only COVID-19 but also other communicable diseases.

Author Contributions MS contributed to the conception and design of the study and drafted the manuscript. FN and BKM contributed to critical revision of the manuscript. All authors read and approved the final manuscript.

\section{Compliance with Ethical Standards}

Funding No sources of funding were used to conduct this study or prepare this manuscript.

Conflict of interest Moslem Soofi, Farid Najafi, and Behzad KaramiMatin have no conflicts of interest that are directly relevant to the content of this article. 


\section{References}

1. World Health Organization (WHO) Emergency Committee. Statement on the second meeting of the International Health Regulations (2005) Emergency Committee regarding the outbreak of novel coronavirus (2019-nCoV). Geneva: WHO. https://www. who.int/news-room/detail/30-01-2020-statement-on-the-secon d-meeting-of-the-international-health-regulations-(2005)-emerg ency-committee-regarding-the-outbreak-of-novel-coronaviru s-(2019-ncov). Accessed 30 January 2020.

2. Chen Y, Liu Q, Guo D. Emerging coronaviruses: genome structure, replication, and pathogenesis. J Med Virol. 2020;92(4):418-23.

3. Wilder-Smith A, Freedman D. Isolation, quarantine, social distancing and community containment: pivotal role for old-style public health measures in the novel coronavirus (2019-nCoV) outbreak. J Travel Med. 2020;27(2):taaa020.

4. Congdon WJ, Shankar M. The role of behavioral economics in evidence-based policymaking. Ann Am Acad Pol Soc Sc. 2018;678(1):81-92.

5. Thaler RH, Sunstein CR. Nudge: improving decisions about health, wealth and happiness. New Haven: Yale University Press; 2008.

6. Thaler RH. Behavioral economics: past, present, and future. Am Econ Rev. 2016;106(7):1577-600.

7. Thaler RH. From cashews to nudges: The evolution of behavioral economics. Am Econ Rev. 2018;108(6):1265-87.

8. Tversky A, Kahneman D. Judgment under uncertainty: heuristics and biases. Science. 1974;185(4157):1124-31.

9. Bickel WK, Moody L, Higgins ST. Some current dimensions of the behavioral economics of health-related behavior change. Prev Med. 2016;92:16-23.

10. Van der Pol M, Cairns J. Descriptive validity of alternative intertemporal models for health outcomes: an axiomatic test. Health Econ. 2011;20(7):770-82.

11. Laibson D. Golden eggs and hyperbolic discounting. Q J Econ. 1997;112(2):443-78.

12. Loewenstein G, Asch DA, Friedman JY, Melichar LA, Volpp KG. Can behavioural economics make us healthier? BMJ. 2012;344:e3482.

13. O'Donoghue T, Rabin M. Doing it now or later. Am Econ Rev. 1999;89(1):103-24.

14. Soofi M, Sari AA, Rezaei S, Hajizadeh M, Najafi F. Individual time preferences and obesity: a behavioral economics analysis using a quasi-hyperbolic discounting approach. Int J Soc Econ. 2019;47(1):16-26.

15. Van Der Pol M, Hennessy D, Manns B. The role of time and risk preferences in adherence to physician advice on health behavior change. Eur J Health Econ. 2017;18(3):373-86.

16. Linnemayr S, Stecher C, Mukasa B. Behavioral economic incentives to improve adherence to antiretroviral medication. AIDS (London, England). 2017;31(5):719.

17. Halpern SD, French B, Small DS, Saulsgiver K, Harhay MO, Audrain-McGovern J, et al. Randomized trial of four financialincentive programs for smoking cessation. N Engl J Med. 2015;372:2108-17.

18. John LK, Loewenstein G, Troxel AB, Norton L, Fassbender JE, Volpp KG. Financial incentives for extended weight loss: a randomized, controlled trial. J Gen Intern Med. 2011;26(6):621-6.

19. Loewenstein G, Brennan T, Volpp KG. Asymmetric paternalism to improve health behaviors. JAMA. 2007;298(20):2415-7.

20. Samuelson W, Zeckhauser R. Status quo bias in decision making. J Risk Uncertain. 1988;1(1):7-59.
21. Johnson EJ, Goldstein D. Do defaults save lives?: American Association for the Advancement of Science; 2003.

22. Chapman GB, Li M, Colby H, Yoon H. Opting in vs opting out of influenza vaccination. JAMA. 2010;304(1):43-4.

23. Aysola J, Tahirovic E, Troxel AB, Asch DA, Gangemi K, Hodlofski AT, et al. A randomized controlled trial of opt-in versus opt-out enrollment into a diabetes behavioral intervention. Am J Health Promot. 2018;32(3):745-52.

24. Watson J, Dreibelbis R, Aunger R, Deola C, King K, Long S, et al. Child's play: harnessing play and curiosity motives to improve child handwashing in a humanitarian setting. Int J Hyg Environ Health. 2019;222(2):177-82.

25. Hussam R, Rabbani A, Reggiani G, Rigol N. Habit formation and rational addiction: a field experiment in handwashing. Harvard Business School BGIE Unit working paper. 2017(18-030).

26. Tversky A, Kahneman D. Prospect theory: an analysis of decision under risk. Econometrica. 1979;47(2):263-91.

27. Luoto J, Carman KG. Behavioral economics guidelines with applications for health interventions. Washington: Inter-American Development Bank; 2014.

28. Kahneman D, Slovic SP, Slovic P, Tversky A. Judgment under uncertainty: heuristics and biases. Cambridge: Cambridge University Press; 1982.

29. Gallagher KM, Updegraff JA. Health message framing effects on attitudes, intentions, and behavior: a meta-analytic review. Ann Behav Med. 2012;43(1):101-16.

30. Weinstein ND. Unrealistic optimism about future life events. J Pers Soc Psychol. 1980;39(5):806.

31. Weinstein ND. Unrealistic optimism about susceptibility to health problems: conclusions from a community-wide sample. J Behav Med. 1987;10(5):481-500.

32. White JS, Dow WH. Intertemporal choices for health. In: Roberto Ch A, Kawachi I, editors, Behavioral economics and public health. Oxford: Oxford University Press, 2015;27:62.

33. Weinstein ND, Marcus SE, Moser RP. Smokers' unrealistic optimism about their risk. Tob control. 2005;14(1):55-9.

34. Dillard AJ, McCaul KD, Klein WM. Unrealistic optimism in smokers: Implications for smoking myth endorsement and selfprotective motivation. J Health Commun. 2006;11(S1):93-102.

35. Matjasko JL, Cawley JH, Baker-Goering MM, Yokum DV. Applying behavioral economics to public health policy: illustrative examples and promising directions. Am J Prev Med. 2016;50(5):S13-S1919.

36. Finucane ML, Alhakami A, Slovic P, Johnson SM. The affect heuristic in judgments of risks and benefits. J Behav Decis Mak. 2000;13(1):1-17.

37. Schwarz N. Feelings-as-information theory. In: Van Lange P, Kruglanski A, Higgins ET, editors. Handbook of theories of social psychology. Thousand Oaks: Sage; 2011. p. 289-308.

38. Peters E, Lipkus I, Diefenbach MA. The functions of affect in health communications and in the construction of health preferences. J Commun. 2006;56:S140-S162162.

39. Slovic P, Peters E. Risk perception and affect. Curr Dir Psychol Sci. 2006;15(6):322-5.

40. Scherer LD, Shaffer VA, Caverly T, Scherer AM, Zikmund-Fisher BJ, Kullgren JT, et al. The role of the affect heuristic and cancer anxiety in responding to negative information about medical tests. Psychol Health. 2018;33(2):292-312.

41. Tong ST, Sopory P. Does integral affect influence intentions to use artificial intelligence for skin cancer screening? A test of the affect heuristic. Psychol Health. 2019;34(7):828-49. 
42. Biran A, Schmidt W-P, Varadharajan KS, Rajaraman D, Kumar $\mathrm{R}$, Greenland K, et al. Effect of a behaviour-change intervention on handwashing with soap in India (SuperAmma): a cluster-randomised trial. Lancet Glob Health. 2014;2(3):e145-e154154.

43. Ariely D. Predictably irrational. New York: Harper Audio New York; 2008.
44. Raafat RM, Chater N, Frith C. Herding in humans. Trends Cognit Sci. 2009;13(10):420-8.

45. Coleman S. The Minnesota income tax compliance experiment: replication of the social norms experiment. Available at SSRN 1393292; 2007. 